\title{
Older people living alone (OPLA) - non-kin-carers' support towards the end of life: qualitative longitudinal study protocol
}

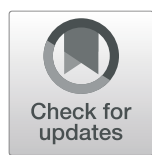

\author{
Sabine Pleschberger ${ }^{1 *}$, Elisabeth Reitinger ${ }^{2}$, Birgit Trukeschitz ${ }^{3}$ and Paulina Wosko ${ }^{1}$
}

\begin{abstract}
Background: A growing number of older people, mainly women, live in single households. They represent a vulnerable group as staying at home may turn out challenging when care needs increase, particularly at the end of life. Non-kin-carers can play an essential role in supporting individuals' preferences to stay at home. In research little attention has been paid to non-kin-carers, such as friends and neighbors, yet. Thus, the Older People Living Alone (OPLA) study will evaluate whether non-kin support is robust enough to enable care dependent people to stay at home even at the end of life. This paper aims to introduce the research protocol.

Methods: We plan to apply a qualitative longitudinal study to better understand how older people living alone and their non-kin-carers manage to face the challenges with increased care needs towards the end-of-life. We will conduct serial interviews with the older persons living alone and their non-kin-carers. A total of 20-25 complete data sets and up to 200 personal interviews were planned. These will be complemented by regular telephone contacts. All interviews will be analysed following the grounded theory approach and strategies for reconstructing case trajectories, supported by MAXQDA software. In the course of the study, inter- and transdisciplinary workshops shall assure quality and support knowledge transfer.

Discussion: This study protocol aims to guide research in a field that is difficult to approach, with regard to its topic, methodology and the interdisciplinary approach. As this study introduces longitudinal qualitative research methodology in the field of home care in Austria, a deeper understanding of (end-of-life-) care trajectories will be enhanced, which is of major relevance for future care planning. With investment in additional reflexivity and communication procedures innovative results and robust knowledge are expected outcomes.
\end{abstract}

Keywords: Older people, Living alone, Non-kin-carers, End-of-life care, Gender issues

\section{Background}

Older people, who live alone, form an increasing group in many countries. In Austria, 51,4\% of all households of people aged older than 65 years were single-households in 2018 [1]. This phenomenon is quite common in Europe, where more than a third of all people at the age group of $65+$ years (31.6\% on average) live alone [2]. This amount is increasing by age and more women are affected than men as data from Austria show: $59 \%$ of all women aged 80 and older lived alone in 2018, while this was the case for only $24.4 \%$ of men of the same age

\footnotetext{
* Correspondence: sabine.pleschberger@goeg.at

${ }^{1}$ Gesundheit Österreich GmbH (GÖG, Austrian Public Health Institute), Vienna, Austria

Full list of author information is available at the end of the article
}

group [3]. As an enormous increase of single-households in the group of $65+$ is expected for the next decades [4], the issue of older people, who live alone, will be of major relevance for many societal systems, particularly for the health and social care systems.

Old age usually comes along with an increased risk of health problems that often also imply comprehensive care needs that need to be met. In the last decades, health and social care systems have been developed and redesigned to support people's preferences for staying at home as long as possible [5]. Older people living alone share these preferences [6] but face enormous challenges due to shortcomings of the wider health and care systems, e.g. the absence of care concepts for this group which sufficiently consider the role of informal carers $[7$,

(c) The Author(s). 2019 Open Access This article is distributed under the terms of the Creative Commons Attribution 4.0 International License (http://creativecommons.org/licenses/by/4.0/), which permits unrestricted use, distribution, and 
8]. However, informal caregivers are not a homogenous group [9]. Informal caregiving is generally understood as family caregiving, whereas little regard has been paid to non-kin-carers, such as friends and neighbors [10].

It is generally understood that older people prefer to 'age in place' rather than move to care homes and this notion is reflected in government policies and services that aim to allow older people aging in place [11, 12]. Certainly, informal care does play a vital role in these arrangements. For older people who live alone these are particularly shaped by their neighborhood and the engagement of non-kin-carers [13, 14]. Usually, these support arrangements do not exist between complete strangers, although the neighborhood relationships are often rather superficial before [15]. The helping arrangements usually develop from so called 'small beginnings' for instance spontaneous support with shopping, transport to hospital or practical repairs [16]. As Van Dijk et al. (2013) put it, 'From nothing it became a lot' [14]. Especially the evolvement of 'bonding relationships' is of interest with regard to staying at home until at last [13].

Research suggests considering different forms of nonkin-carers, such as neighbors or friends, who differ with regard to motivation, assumption of tasks and intensity of involvement $[16,17]$. In a Canadian study, neighbors as informal carers turned out to be much younger than caring friends. On average, however, friends invested more hours per week supporting their friend in need [18]. An exploratory study commissioned by the Austrian Ministry of Social Affairs on older people living alone with increasing care needs shed light on the substantial involvement of non-kin carers [10]. It is important to determine whether this kind of support can be robust enough to enable staying at home even at the end of life.

Place of care and place of death are important for the quality of end-of-life care. Against this background, 'dying with dignity', which for most people living alone is synonymous with staying at home for as long as possible, is one of the most important "existential considerations" [6]. Though older people living alone possess various strategies to remain independent, they turn out to be vulnerable, due to their difficult living situations, limited resources or lack of support [19]. Hanratty et al. (2013) estimated chances of older people who lived alone to stay at home for as long as possible as very pessimistic, but the prospect of moving into a nursing home was seen as a real source of anxiety by them [20]. Further studies confirm that it is mainly a lot of concerns which make older people change their minds and shift their preferences from home to inpatient settings in the course of their last years and months [21, 22].

Literature does not provide a cohesive picture of nonkin involvement in end-of-life care but rather snapshots as illustrated in a scoping review [10]: Burns et al. (2011) found that friends tended to involve specialist palliative care services earlier and more often than family members did [17]. Furthermore, the need for Advance Care Planning might be more evident in case of older people living alone than when family carers are in the same home [23]. As this is not common practice, the person's wish to die at home can easily be jeopardized [24].

Finally, gender represents and is represented within the societal power structures. The gendered system leads to a gendered division of (paid and unpaid) labor, and with this study we will shed light on both areas, as care work is mainly defined as "female" work [25].

In terms of family caregiving studies have highlighted the gendered nature of caregiving, indicating that women have been positioned as caregivers by health care providers as well as by family members $[26,27]$. While men provided care mostly to their spouses, women took care for a broader range of people including partners, siblings, parents [28]. Most of the research on gender relations in hospice palliative home care has focused on sex and gender differences [29]. Limited exploration of how and why gendered processes are enacted in the various contexts and setting has been done yet. In order to change practice it is vital to better understand the "doing gender" in care for older people [30-32].

This paper presents the design of the research project on "Older People Living Alone (OPLA)". The research project puts a focus on a so far neglected though increasingly relevant group of society, which is older people living alone with long-term conditions who receive support by non-kin-carers. The aims of the project are to [1] better understand the challenges that older people living alone face in light of increasing care needs towards the end of life, [2] analyse the potential of non-kin-carers in care arrangements of older people living alone and identify gender specific patterns therein, [3] work out characteristics of different arrangements which support older people's preferences for staying at home including access to palliative care, [4] identify areas of improvement in the Austrian long-term care system with regard to supporting older people living alone including end-of-life care.

\section{Methods}

In order to get an in-depth understanding of the challenges of older people living alone and the contribution of their non-kin-carers longitudinal case studies shall be generated through serial interviews [33, 34]. With this prospective longitudinal study design, we would like to overcome some of the shortcomings we usually face in end-of-life research:

- We know from research in the field of family caregiving that the burdens of care emerge from the duration of the care relationship and its progressive 
character as well as adaption processes have to be considered [35]. To better capture the dynamics in the relationships and care arrangements between informal carers and older persons it is essential to interview them more than only once and prospectively [36, 37].

- A longitudinal approach allows a better understanding of older people's needs and preferences which might change towards the end of life [38, 39].

- Caregivers' experiences with end-of-life care and their narratives differ when collected in retrospect, as mourning and grief and/or relief of burden influence perspectives [40, 41]. Therefore, a prospective design will reveal more robust information concerning support needs throughout the process of care including time of bereavement.

\section{Sampling and recruitment}

The main target population of this study includes people living alone in a progressive state of illness or frailty being supported by an informal non-kin-carer, regardless of the intensity or character of support. As this applies to all qualitative studies, sampling does not aim at representativity [42]. Instead, the sampling aims to cover abroad variety of older people living alone at the end of life and their non-kin-carers in Austria.

Older people living alone and their non-kin carers are not easy to approach [24]. Therefore, various strategies will be applied, in order to avoid sampling bias and cover a broad variety of care arrangements (see Table 1).

Recruitment will take place in four Austrian regions, Styria, Upper Austria, Lower Austria and Vienna in order to cover rural areas (Styria, Upper and Lower Austria) as well as urban areas (Graz in Styria and Vienna). The regions involved cover about $58 \%$ of the Austrian federal territory and $71 \%$ of the Austrian population.

Gatekeepers should inform the target group (care dependent people being looked after by a neighbor or friend) about the study and hand out an information sheet to potential participants. Upon agreement by the latter, gatekeepers will pass on contact details to the research team, which will get in touch with participants, explain the research aims and ask for consent.

Table 1 Access to the field

\begin{tabular}{ll}
\hline Gatekeeper & Aiming to recruit ... \\
\hline $\begin{array}{l}\text { Home care services } \\
\text { care services }\end{array}$ & ... older people living alone without a specific disease \\
General Practitioners & $\begin{array}{l}\text {... care arrangements independent of involvement } \\
\text { of professional care services (via older people living } \\
\text { alone as well as non-kin-carers who are patients } \\
\text { of GP) }\end{array}$ \\
\hline
\end{tabular}

\section{Sampling criteria}

A qualitative sampling strategy will be applied in order to cover some basic characteristics, which are relevant for this study, such as a) type of relationship to informal carer, b) gender and c) progression of disease [43].

a) We are aiming to differentiate the group of non-kin-carers in our sample to work out the specific characteristics and challenges with regard to relationships: Neighbors and friends as non-kin-carers shall be part of the sample quite evenly.

b) We consider gender a relevant criterion for sampling as we are aiming to include various combinations with regard to patients and carers. Considering the groups of interest here an overrepresentation of females seems to be inevitable - especially on the side of older people living alone. In order to contrast gendered phenomena like involvement in physical aspects of care, we look out to include about 8-10 male non-kin-carers and 6-8 older men living alone.

c) Older people living alone should be included in a progressive state of their disease and/or stage of frailty in order to raise the probability to represent end-of-life issues in the trajectories. The only exclusion criterion is the inability to participate, for example, because of dementia, an immediately life threatening illness or a situation of crisis.

As we are aiming to include the end-of-life phase in the process observed it seems essential to consider progression of disease or frailty as a criterion for inclusion. Keeping in mind that this is a difficult endeavor, we will try to approach this by suggesting health professionals to reflect the "surprise question" when screening their records to identify potential participants: "Would you be surprised if this person were to die within the next year?" This indicator has proven useful in a similar study [39].

\section{Timing and number of interviews}

The aim is to capture change as it happens, and to respond to the individual dynamics in the care arrangements towards the end of life. For this reason, this study is designed along serial interviews with flexible intervals, as suggested by Carduff et al. (2015): After a baseline interview, we plan to conduct three personal interviews with the older person and the nominated non-kin-carer at least every 6 months over a period of 18 months. Telephone contacts with participants in between (about every 6 weeks) should ensure contact and help identify "critical situations" [44].

In case a patient dies within this period a retrospective interview (RI) will be performed with his/her main informal caregiver, about 3-5 months after the patient's 
death. This extends the total period of data collection to up to approximately 20 months per case.

Pinnock et al. (2011) suggest that a total of 16-20 complete data-sets are necessary in order to reach sufficient data for profound analysis [39]. As we are aiming to contrast within our sample relating to selected criteria (gender issues as well as different types of non-kin-carers) we exceed this number to 20-25 complete data sets. The latter consist of those cases where we manage to conduct interviews at least at two points of time (longitudinal), as well as collecting data from the older person living alone and a non-kin-carer at each instant (two perspectives).

In longitudinal studies, attrition has to be considered. A certain drop out within the period of 18 months has to be expected either due to rapid progression and "hastened death" or other causes (withdrawal, non-ability to be interviewed due to worsening condition) [34]. However, most of these incidents are unavoidable in this group of interest, so we work with the construct of a minimum data set (see above). Furthermore, we engage in building sustainable relationships with the participants throughout the process. Regular telephone contacts will also contribute to reduce attrition [44]. Hence, we are planning to start with recruitment of about 30 cases at the onset, to gain a total of 2025 complete data sets in order to avoid oversampling [33]. Apart from the length of the trajectories additional variability evolves from interviews which will be conducted jointly, as well as additional personal interviews due to acute crisis where necessary. The older people and their non-kin-carers will be interviewed separately, however, if they want to do one or more joint interviews we would allow this, too [34, 39].

In light of this, it is difficult to calculate an exact number of interviews planned. Therefore, we work with approximate numbers. We estimate an average value of about 180 interviews to be conducted within the study period. This number considers a minimum of 80 interviews with older people living alone and/or non-kin carers up to a maximum of 225 interviews as presented in Table 2.

\section{Data collection}

To generate the data-sets for the case studies serial interviews with the older person living alone and/or her nonkin-carers will be conducted. We would like to collect the two perspectives separately, however, if preferred, we would also interview simultaneously [34, 39]. To build up a trustful and sustainable relationship, which is crucial for longitudinal studies, all interviews within a trajectory shall be conducted by the same interviewer [45]. We apply narrative interviews as narratives have proven to produce the most suitable and saturated data to present perspectives of people on end-of-life issues $[45,46]$.

The initial interviews serve two goals. On the one hand, they aim to build a trustful relationship between
Table 2 Number of interviews

\begin{tabular}{|c|c|c|c|c|c|c|}
\hline \multicolumn{7}{|c|}{ Number of interviews per data set/case } \\
\hline Time & TO & $\mathrm{T} 1$ & $\mathrm{~T} 2$ & $\mathrm{~T} 3$ & $\mathrm{Rl}^{\mathrm{b}}$ & Sum \\
\hline Min & $1 / 1^{a}$ & $1 / 1$ & & & $+/ 0$ & 4 \\
\hline \multirow[t]{2}{*}{ Max } & $1 / 1$ & $1 / 1$ & $1 / 1$ & $1 / 1$ & $+/ 1$ & 9 \\
\hline & \multicolumn{5}{|c|}{ Number of interviews (Range): } & $4-9$ \\
\hline \multicolumn{7}{|c|}{ Number of data sets/cases } \\
\hline \multirow[t]{2}{*}{ Time } & T0 & $\mathrm{T} 1$ & $\mathrm{~T} 2$ & T3 & $\mathrm{Rl}$ & Sum \\
\hline & 30 & $\ldots \epsilon$ & ted a & nove & & $20-25$ \\
\hline \multicolumn{7}{|c|}{ Number of interviews in total } \\
\hline Min & $20 d c$ & ts á & views & & & 80 \\
\hline Max & $25 d c$ & ts á & views & & & 225 \\
\hline \multicolumn{6}{|c|}{ Estimated number of interviews (Calculated range: 80-225) } & $\sim 180$ \\
\hline
\end{tabular}

Notes: ${ }^{\mathrm{a}}$ (Older person/Non-kin-carer), ${ }^{\mathrm{b}}$ (RI Retrospective Interview)

researcher and participant [47]. This will be crucial in order to get high quality data and to motivate people for serial interviews [33]. Secondly, it is necessary to include information about the biography and current situation of the older people as well as their informal carers in order to make sense of the data. An interview guide will be prepared and piloted before starting the first baseline collection of data. It serves to capture the range and depth of the subject's experiences, while being sufficiently flexible to enable the interviewer to respond to individual concerns. Interviews with non-kin-carers will aim to explore motivation for their commitment as well as limits or prior experiences with caring.

The follow-up interviews will be conducted by the same researcher as the initial interviews and will start with open stimuli to allow the participants to provide an update of their situation including key events in the foregoing weeks. Some issues will be checked regularly as integrated in a follow-up-interview guide, e.g. ideas about the future or issues of relationship between non-kin-carers and persons in need of care. The interview guide for the follow-up interviews will also consist of an individual part depending on the situation and dynamics of each case. This latter part will be informed by the telephone conversations between the personal interviews.

The telephone-interviews will consist of one or two questions aiming to recall the study and collect contextual information to the current situation of the care arrangement. The calls shall not be recorded to keep them quite informal and to build trust. However, the researcher will take notes right after the telephone call and these notes will be part of the data pool for analysis as well as useful information for the subsequent personal interviews.

In case of death of an interviewee, we will conduct a retrospective interview with the non-kin-carer. The aim of this interview is to focus on the last phase of life and specific conditions and challenges in the last days, as well 
as after death. Issues of bereavement in non-kin-carers will be part of these interviews, too. Timing of these retrospective interviews will depend on the non-kin-carer. Interviews with bereaved family members usually are conducted 3-5 months after death of the person [40], but an individual variation according to the closeness of the relationship as well as personal characteristics of the nonkin-carers have to be considered in this study.

All personal interviews will be voice-recorded and transcribed verbatim. Additionally, field notes and postscripts will be provided on the context and course of the interviews as well as the telephone conversations.

\section{Data analysis \& Synthesis}

Analysis of the data aims to provide case studies, which illustrate key issues within a process of care including perspectives of older people living alone and their nonkin-carers. Therefore, we refer to strategies applied in longitudinal case study research (e.g. $[48,49])$ as well as the grounded theory approach. The latter is used when little is known about the area of interest and it focuses on identifying, describing and explaining interactional processes in a social context [50].

Analysis will be iterative throughout the study, which allows to condense emerging themes and phenomena within trajectories as well as to inform subsequent interviews [51]. We will apply MAXQDA software to manage qualitative data, specifically for coding as well as for comparison within and across cases and trajectories [52]. The aim is to create a narrative of the case, in order to work out key phenomena according to the research questions. In light of these, analysis should also result in a systematically characterization of different care arrangements which support older people's preferences for staying at home.

In addition to the analysis of trajectories, we will conduct cross-sectional analysis for selected data-sets, e.g. baseline interviews with the older people living alone and the non-kin-carers as well as retrospective interviews with bereaved non-kin-carers [36]. To this end, the data will be coded using MAXQDA software and categories will be arranged in order to work out key phenomena and formulate theoretical assumptions following grounded theory methodology in a constructivist understanding as suggested by [53].

\section{Quality assurance}

In qualitative research, and especially in end-of-life studies support for the researcher is essential in order to ensure high quality data and avoid distancing and/or overinvolvement [54]. As this is a longitudinal study specific risks have to be considered, such as over-rapport [33] or concerns with regard to death and dying of participants. However, it is important to reflect upon these. Beyond ongoing supervision by the project leader throughout the study the research team will require counseling by an external supervisor (psychologist) to address burdensome experiences during the fieldwork.

\section{Inter- \& Transdisciplinary Reflective Workshops}

Through reflective workshops, we aim at theory building throughout the research process. Theoretical issues of this study, such as gender or quality of care in formal and informal settings, will be of interest, as well as ethical, methodological and practical aspects of conducting the research project. Investing in quality assurance of the research is a major concern.

In order to capture this, we plan up to three half-day workshops a year. The core team will reflect with the cooperation partners in up to two interdisciplinary workshops (int-WS) per year. This will be complemented/amended by annually transdisciplinary workshops (trans-WS), including representatives of non-academic stakeholder groups like NGO's and informal carer interest groups.

A facilitator who is not a member of the research team but familiar with qualitative research in end-of-life care should guide these discussions. This has proven to be good practice in inter- and transdisciplinary research settings [55]. For each of these meetings, relevant material will be prepared beforehand by the core-team, and a written protocol will be made afterwards to note the key issues (see Table 3).

\section{Project schedule}

This research project will last from March 2018 to February 2021 (36 months).

\section{Phase 1 - preparation (3-6 Mon)}

This phase will consist of an update of the literature and the state of research. Further submission of application for ethical review at the relevant ethic committees is a key activity as well as providing field access and preparing fieldwork.

\section{Phase 2 - data collection \& fieldwork (20-24 Mon)}

The conduct of baseline and serial interviews, regular telephone contacts as well as the retrospective interview are core activities. Each trajectory will be followed up to 18 months. Considering a consecutive start of data

Table 3 Workshop schedule

Year One: Reflection on process of recruitment and sampling, Specific analysis and comparison of literature on gender issues and formal-informal care encounters in home care, Developing interview guides (two int-WS, one trans-WS)

Year Two: Reflection on the interview dynamics, Reflection on Analysis of baseline interviews (one int-WS, one trans-WS)

Year Three: The process of developing case studies, Discussing case studies, Synthesis of results, Presenting data \& Dissemination (two int-WS, one trans-WS) 
collection as well as a period of $3-5$ months after death for a retrospective interview we calculate a period of 24 months for fieldwork.

\section{Phase 3 - analysis (22 Mon)}

Data analysis is an iterative process and will start parallel to data collection, however, intensity will vary over time, e.g. analysis of baseline interviews, development of case studies, etc.

\section{Phase 4 - synthesis \& discussion (6 Mon)}

The last 6 months of this study will focus on systematically comparing results from analysis and discussion in light of the various theoretical discourses.

\section{Phase 5 - dissemination (6 Mon+)}

While a narrow focus on disseminating the results at different levels is put on in the last phase of the study, earlier dissemination will happen in the way of presentations given at conferences or papers written. This interdisciplinary study aims to address various scientific communities (e.g. nursing science, public health, gerontology, geriatrics, social sciences) as well as health care professionals and service providers including the wider public. We put a focus on Austria when approaching health professionals, service providers and interest groups with the conduct and results of this study. Apart from involving non-academic stakeholders in the planned annual transdisciplinary workshops, we will contribute with presentations at national conferences or meetings as well as project letters which will be disseminated through websites of the institutes involved as well as partners like the Austrian Interest group of informal caregivers.

\section{Discussion}

Non-kin-care for older people living alone has to be considered underexplored, at least in the German speaking context, which has to do with the residual development of gerontology as well as nursing research or health care services research. However, including a focus on end-of-life and gender issues in this non-organized field of care is innovative even for the wider international scientific community. When looking at formal-informal care encounters the focus is either on family caregivers or on voluntary work (organized forms). Apart from this, the gender perspective, relevant in both, recipients and providers of care, will provide new insights into new ways of coping with challenges.

Widening the perspectives of care arrangements through going beyond family-relationships and reaching out to develop a culture of care in society is a major contribution we expect from this work, as non-kin-care arrangements are exemplary for civic involvement in care. To promote these forms of engagement we need basic research in this field to better understand motivation and needs of these carers. This allows new perspectives on collaboration between civic engagement and professional services in a welfare mix which extends traditional understandings of informal caregiving members [56].

This study protocol introduces longitudinal qualitative research methodology [57] in the field of home care, which is a rather young development in palliative care research and has not been conducted in Austria so far. Most research is limited to snapshots, but this approach allows investigating the procedural aspects of care, including decision-management in the trajectories towards the end of life. In addition, this study is interdisciplinary by nature, and the research team has different backgrounds, including gerontology, nursing and health care sciences, palliative care and health economics. Investing in additional reflexivity and communication procedures creates innovative results and robust knowledge as outcomes [55].

\section{Abbreviations}

EC: Ethics Committee; FWF: Austrian Science Fund; GP: General Practitioner; OPLA: Older People Living Alone; Rl: Retrospective Interview; WS: Workshop

\section{Acknowledgements}

The development of the study protocol and application for funding were first proceeded when SP and PW were affiliated to the Paracelsus Medical University Salzburg, and ER to the Interdisciplinary Faculty at the University of Klagenfurt. Resubmission of the grant application took place under the auspices of Austrian Platform for Interdisciplinary Research on Ageing, Vienna, where SP was appointed at that time. The Research Institute for Economics of Aging at the Vienna University of Economics and Business thanks the Vienna Social Fund for supporting its scientific work. Finally, we would like to thank Gabriele Müller-Mundt, Hannover Medical School, for her kind advice on methodological issues.

\section{Authors' contributions}

SP and PW drafted the manuscript, SP was responsible for the grant application. SP, PW, ER \& BT contributed to the design of the study. All authors read and approved the final paper.

Funding

The study is funded by the Austrian Science Fund (FWF); grant number: $P$ 30607-G29 (study duration March 2018 to February 2021). The funding body had no role in the design of the study and had no influence on creating this manuscript.

\section{Availability of data and materials Not applicable.}

\section{Ethics approval and consent to participate}

The Ethics Committee for the federal state of Lower Austria has approved the study in August 2018 (EC number: GS4-EK-18/005-2018). Written informed consent will be sought from all participants for the baseline interviews, subsequent interviews will be conducted based on oral consent. In the process of transcription all personal data will be anonymized, like names of towns, persons or organizations.

\section{Consent for publication}

Not applicable.

\section{Competing interests}

The authors declare that they have no competing interests.

\section{Author details}

${ }^{1}$ Gesundheit Österreich GmbH (GÖG, Austrian Public Health Institute), Vienna, Austria. ${ }^{2}$ Department of Nursing Science, University of Vienna, Vienna, 
Austria. ${ }^{3}$ Research Institute for Economics of Aging, Vienna University of Economics and Business, Vienna, Austria.

\section{Received: 18 July 2019 Accepted: 6 August 2019} Published online: 13 August 2019

\section{References}

1. Statistik Austria. Mikrozensus-Arbeitskräfteerhebung 2018. Privathaushalte nach Haushaltsgröße, Bundesländern und Alter der Haushaltsreferenzperson-Jahresdurchschnitt 2018: Statistik Austria 2018. Available from: https://www.statistik.at/web_de/statistiken/menschen_und_ gesellschaft/bevoelkerung/haushalte_familien_lebensformen/haushalte/0233 02.html. Accessed 25 June 2019.

2. Statistisches Bundesamt (Hg.). Bevölkerung und Erwerbstätigkeit-Haushalte und Familien. Ergebnisse Mikrozensus 2017. 2018 Available from: https:// www.destatis.de/DE/Themen/Gesellschaft-Umwelt/Bevoelkerung/HaushalteFamilien/Publikationen/Downloads-Haushalte/haushalte-familien-20103001 77004.pdf? _blob=publicationFile\&v=4. Accessed 25 June 2019.

3. Austria S. Mikrozensus-Arbeitskräfteerhebung. Lebensformen nach Geschlecht und Alter- Jahresdurchschnitt 2018: Statistik Austria 2018. Available from: https://www.statistik.at/web_de/statistiken/menschen_und_ gesellschaft/bevoelkerung/haushalte_familien_lebensformen/lebensformen/ 023305.html. Accessed 25 June 2019.

4. Austria S. Haushaltsprognose 2018. Repräsentanten von Ein- und Mehrpersonenhaushalten 2011-2080 nach Alter und Geschlecht: Statistik Austria; 2018 [Available from: https:/www.statistik.at/web_de/statistiken/ menschen_und_gesellschaft/bevoelkerung/demographische_prognosen/ haushaltsprognosen/023533.html. Accessed 25 June 2019.

5. Health Do. End of Life Care Strategy. Promoting high quality care for all adults at the end of life. London: Department of Health; 2008. [Available from: https://assets.publishing.service.gov.uk/government/uploads/system/ uploads/attachment_data/file/136431/End_of_life_strategy.pdf. Accessed 25 June 2019

6. Aoun S, Kristjanson L, Oldham L, Currow D. A qualitative investigation of the palliative care needs of terminally ill people who live alone. Collegian. 2008;15(1):3-9.

7. Schaeffer D, Ewers M. Versorgung am Lebensende in Gesellschaften des langen Lebens. Pflege \& Gesellschaft. 2013;18(2):153-68.

8. Seamark D, Blake S, Brearley SG, Milligan C, Thomas C, Turner M, et al. Dying at home: a qualitative study of family carers' views of support provided by GPs community staff. Br J Gen Pract. 2014;64(629):e796-803.

9. Trukeschitz B, Sengschmid T, Schneider U. Versteckte Kosten der Angehörigenpflege: Die psychosoziale Belastung pflegender Angehöriger. In: Appelt E, Fleischer E, Preglau M, editors. Elder Care Intersektionelle Analysen der informellen Betreuung und Pflege alter Menschen in Österreich Demokratie im. Innsbruck: Studienverlag; 2014. p. 113-30.

10. Pleschberger $S$, Wosko P. Informal non-kin support for elderly people living alone and end of life care. Literature review. Z Gerontol Geriatr. 2015;48(5):457-64.

11. Genet N, Boerma W, Kroneman M, Hutchinson A, Saltman RB. Home care across Europe. Current structure and future challenges. European Observatory on Health Systems and Policies: Copenhagen; 2012.

12. Hedtke-Becker A, Hoevels R, Otto U, Stumpp G. Selbstbestimmt bis zum Lebensende zu Hause bleiben - Strategien niederschwelliger Hilfen und psychosozialer Beratung für alte Menschen und ihr Umfeld. In: Hahn G, Ghaleitner S, editors. Jahrbuch Klinische Sozialarbeit V Übergänge gestalten Lebenskrisen und psychosoziale Übergänge. Bonn: Psychiatrie Verlag; 2011. p. 246-60.

13. Walker RB, Hiller JE. Places and health: a qualitative study to explore how older women living alone perceive the social and physical dimensions of their neighbourhoods. Soc Sci Med. 2007;65(6):1154-65.

14. van Dijk HM, Cramm JM, Nieboer AP. The experiences of neighbour, volunteer and professional support-givers in supporting community dwelling older people. Health Soc Care Community. 2013;21 (2):150-8.

15. Barker JC. Neighbors, friends, and other nonkin caregivers of community-living dependent elders. J Gerontol B Psychol Sci Soc Sci. 2002;57(3):S158-67.

16. Nocon $A$, Pearson $M$. The roles of friends and neighbours in providing support for older people. Ageing Soc. 2000;20(03):341-67.

17. Burns CM, Abernethy AP, Leblanc TW, Currow DC. What is the role of friends when contributing care at the end of life? Findings from an Australian population study. Psychooncology. 2011;20(2):203-12.
18. Lapierre TA, Keating N. Characteristics and contributions of non-kin carers of older people: a closer look at friends and neighbours. Ageing Soc. 2013; 33(08):1442-68.

19. Haslbeck JW, McCorkle R, Schaeffer D. Chronic illness self-management while living alone in later life: a systematic integrative review. Res Aging. 2012;34(5):507-47.

20. Hanratty B, Addington-Hall J, Arthur A, Cooper L, Grande G, Payne S, et al. What is different about living alone with cancer in older age? A qualitative study of experiences and preferences for care. BMC Fam Pract. 2013;14:22.

21. Gomes B, Calanzani N, Gysels M, Hall S, Higginson IJ. Heterogeneity and changes in preferences for dying at home: a systematic review. BMC Palliat Care. 2013;12(1):7.

22. Gott M, Seymour J, Bellamy G, Clark D, Ahmedzai S. Older people's views about home as a place of care at the end of life. Palliat Med. 2004;18(5):460-7.

23. Ke L-S, Huang $X$, Hu W-Y, O'Connor M, Lee S. Experiences and perspectives of older people regarding advance care planning: a meta-synthesis of qualitative studies. Palliat Med. 2017;31(5):394-405.

24. Pleschberger S, Wosko P. From neighbour to carer: an exploratory study on the role of non-kin-carers in end-of-life care at home for older people living alone. Palliat Med. 2017;31(6):559-65.

25. Fast J, Keating N, Otfinowski P, Derksen L. Characteristics of family/friend care networks of frail seniors. Can J Aging. 2004;23(1):5-19.

26. Eriksson H, Sandberg J, Hellström I. Experiences of long-term home care as an informal caregiver to a spouse: gendered meanings in everyday life for female carers. Int J Older People Nursing. 2013;8(2):159-65.

27. Ussher JM, Sandoval M. Gender differences in the construction and experience of cancer care: the consequences of the gendered positioning of carers. Psychol Health. 2008;23(8):945-63.

28. Perz J, Ussher JM, Butow P, Wain G. Gender differences in cancer carer psychological distress: an analysis of moderators and mediators. Eur J Cancer Care. 2011;20(5):610-9.

29. Köhler N, Perner A, Anders D, Brähler E, Papsdorf K, Götze H. Family caregivers of palliative cancer patients: health-related quality of life and care-related burden. Psychother Psychosom Med Psychol. 2012;62(5):157-62.

30. West C, Zimmerman DH. Doing gender. Gend Soc. 1987;1(2):125-51.

31. Reitinger $E$, Heimerl $K$. Ethics and gender issues in palliative care in nursing homes: an Austrian participatory research project. Int J Older People Nursing. 2014;9(2):131-9,

32. Reitinger $\mathrm{E}$, Lehner $\mathrm{E}$, Pichler $\mathrm{B}$, Heimerl K. "Doing gender" in a nursing home for the elderly: Perspektives of staff and management. Z Gerontol Geriatr. 2016;49(8):700-5.

33. Calman L, Brunton L, Molassiotis A. Developing longitudinal qualitative designs: lessons learned and recommendations for health services research. BMC Med Res Methodol. 2013;13:14.

34. Müller-Mundt G, Bleidorn J, Geiger K, Klindtworth K, Pleschberger S, Hummers-Pradier $\mathrm{E}$, et al. End of life care for frail older patients in family practice (ELFOP)-protocol of a longitudinal qualitative study on needs, appropriateness and utilisation of services. BMC Fam Pract. 2013;14(1):52.

35. Stajduhar K, Funk L, Toye C, Grande G, Aoun S, Todd C. Part 1: home-based family caregiving at the end of life: a comprehensive review of published quantitative research (1998-2008). Palliat Med. 2010;24(6):573-93.

36. Kendall M, Murray SA, Carduff E, Worth A, Harris F, Lloyd A, et al. Use of multiperspective qualitative interviews to understand patients' and carers' beliefs, experiences, and needs. BMJ. 2009;339:b4122.

37. Kreyer $C$, Pleschberger S. Struggling for normal in an instable situation informal caregivers self-management in palliative home care. A metasynthesis. Pflege. 2014;27(5):307-24.

38. Murray SA, Kendall M, Carduff E, Worth A, Harris FM, Lloyd A, et al. Use of serial qualitative interviews to understand patients' evolving experiences and needs. BMJ. 2009;339:b3702.

39. Pinnock $H$, Kendall M, Murray SA, Worth A, Levack P, Porter M, et al. Living and dying with severe chronic obstructive pulmonary disease: multiperspective longitudinal qualitative study. BMJ. 2011;342:d142.

40. Addington-Hall J, McPherson C. After-death interviews with surrogates/ bereaved family members: some issues of validity. J Pain Symptom Manag. 2001;22(3):784-90

41. Pleschberger $\mathrm{S}$. Recognizing dying in palliative home care. Final report project L376-G14. Vienna: Translational Research Program of the FWF; 2011.

42. Luborsky MR, Rubinstein RL. Sampling in qualitative research: rationale, issues, and methods. Res Aging. 1995;17(1):89-113. 
43. Morse JM. Strategies for sampling. In: Morse JM, editor. Qualitative nursing research: a contemporary dialogue. Newbury Park: Sage; 1991. p. 127-45.

44. Carduff E, Murray SA, Kendall M. Methodological developments in qualitative longitudinal research: the advantages and challenges of regular telephone contact with participants in a qualitative longitudinal interview study. BMC Res Notes. 2015;8:142.

45. Carduff E, Finucane A, Kendall M, Jarvis A, Harrison N, Greenacre J, et al. Understanding the barriers to identifying carers of people with advanced illness in primary care: triangulating three data sources. BMC Fam Pract. 2014;15:48.

46. Pleschberger S, Seymour JE, Payne S, Deschepper R, Onwuteaka-Philipsen $B D$, Rurup ML. Interviews on end-of-life care with older people: reflections on six european studies. Qual Health Res. 2011;21(11):1588-600.

47. Payne S. Interview in qualitative research. In: Memon $A$, Bull $R$, editors. Handbook of the psychology of interviewing. Chichester: Wiley; 1999. p. 89-102.

48. Hildenbrand B. Fallrekonstruktive Familienforschung: Anleitungen für die Praxis. Opladen: Leske \& Budrich; 2005.

49. Thomson R. The qualitative longitudinal case history: practical, methodological and ethical reflections. Soc Policy Soc. 2007;6(4):571-82.

50. Birks M, Mills J. Grounded theory: a practical guide. London: Sage; 2011.

51. Strauss A, Corbin J. Basics of qualitative research techniques. 2 nd ed. Thousand Oaks: Sage publications; 1998.

52. Kuckartz U. Qualitative text analysis: a guide to methods, practice and using software. London: Sage Publications Ltd; 2014

53. Charmaz K. Constructing grounded theory. 2nd ed. London: Sage; 2014.

54. Dickson-Swift V, James EL, Kippen S, Liamputtong P. Risk to researchers in qualitative research on sensitive topics: issues and strategies. Qual Health Res. 2008;18(1):133-44.

55. Reitinger E, Krainer L, Zepke G, Lehner E. Kommunikation beobachten, ihr einen Rahmen geben und sie reflektieren. In: Dressel G, Berger W, Heimerl K, Winiwarter V, editors. Interdisziplinär und transdisziplinär forschen Praktiken und Methoden. Bielefeld: Transcript; 2014. p. 135-49.

56. Wegleitner K, Heimerl K, Kellehear A. Compassionate communities: case studies from Britain and Europe. London and New York: Routledge; 2015.

57. Flick U. Designing qualitative research. London et al: Sage; 2007.

\section{Publisher's Note}

Springer Nature remains neutral with regard to jurisdictional claims in published maps and institutional affiliations.

Ready to submit your research? Choose BMC and benefit from:

- fast, convenient online submission

- thorough peer review by experienced researchers in your field

- rapid publication on acceptance

- support for research data, including large and complex data types

- gold Open Access which fosters wider collaboration and increased citations

- maximum visibility for your research: over $100 \mathrm{M}$ website views per year

At $\mathrm{BMC}$, research is always in progress.

Learn more biomedcentral.com/submissions 